\title{
Mouse Strain Dependent and Independent Effects of Type 1 Diabetic Bone Pathology
}

Jing Zhang\#, Lindsay Coe\#, Katherine J Motyl and Laura R McCabe*

Departments of Physiology and Radiology, Michigan State University, USA

\#Authors contributed equally to the manuscript

\begin{abstract}
Type 1 diabetes (T1D) contributes to bone loss in humans as well as in both spontaneous and pharmacologicinduced T1D mouse models. The severity of complications of T1D, such as nephropathy, differs in different mouse strains. However, the contribution of genetics in modifying the extent of T1D-induced bone loss has not been fully addressed. Here, we compare the T1D-induced bone pathology between three commonly used inbred mouse strains: Balb/c, C57BL/6 and 129/Sv mice. All T1D mouse strains displayed a characteristic bone phenotype characterized by significant bone loss, decreased levels of osteoblast markers and increased marrow adiposity. However, straindependent differences were also observed. Most notably, 129/Sv T1D mice displayed the greatest magnitude of bone loss despite having the least disease severity (as indicated by blood glucose levels) of the three strains studied. These findings suggest the contribution of strain dependent/genetically associated factors to the degree of bone loss observed in T1D mice.
\end{abstract}

Keywords: Bone; Osteoblast; Diabetes; Strain; Genotype; Marrow adiposity; Osteoporosis

\section{Introduction}

Type 1 diabetes (T1D) is a metabolic disease, characterized by hypoinsulinemia and thyperglycemia that has profound effect on the bone $[1,2]$. Human and animal models of T1D display diminished bone mineral apposition rate (MAR), bone mineral density (BMD) and bone mineral content (BMC) $[3,4]$. Potential contributors to the pathogenesis of T1D bone loss include disturbed glucose metabolism $[5,6]$ systemic and bone marrow inflammation [7-9], changes in lipid metabolism [10-12], and changes in systematic hormones [13] (Figure 1). Bone marrow adiposity, which can promote bone oss1, may play less of a role in T1D osteoporosis $[1,14,15]$, but is a key marker of the diabetic bone pathology in mice. All of the above parameters are regulated by a many factors including the environment and genetics. Genetics has been shown to influence the severity of several complications of T1D, including nephropathy [16]. However, the contribution of genetics in modifying the extent of T1D-induced bone loss has not been fully addressed.

Animal models are critical for examining and identifying mechanisms of T1D bone phenotype, including the role of genetics. Inbred mice offer unlimited numbers of genetically identical "twins" [17-19] whose environments can be strictly controlled. Comparisons among mouse strains have been used to identify genetic loci that contribute to levels of bone density in healthy mice. Genome-wide analysis indicates that chromosomes 1,4,8,13 and 14 harbor quantitative trait loci that affect bone phenotypes in the inbred $\mathrm{C} 3 \mathrm{H}$ and $\mathrm{C} 57 \mathrm{BL} / 6$ mice [20]. Similar analyses performed on C57BL/6 and 129/Sv mice identified Bmd20 on chromosome 6 and Bmd22 on Chromosome 1 as contributing to both total body and vertebral BMD levels [21]. Genetic variation in such areas could impact skeletal stem cell lineage differentiation [22], inflammation, metabolism, and hormone levels that ultimately regulate osteoblast and osteoclast activities.

Bone architecture also displays strain specificity. A study comparing the bone phenotypes in 29 different inbred strains found significant variation in femur cross-sectional area, density, and mechanical properties [23]. Specifically, Balb/c mice had greater femur length compared to $129 / \mathrm{J}$ and C57BL/6J mice, and C57BL/6 mice had lower $\mathrm{BMD}$ compared to Balb/c and 129/J mice [23]. Other studies found that compared to C57BL/6 mice [24], $\mathrm{C} 3 \mathrm{H}$ mice had thicker femoral and vertebral cortices, higher BMD and smaller medullary cavities, despite having similar body size and weight $[25,26]$. Differences in osteoblast and osteoclast activities (bone remodeling rates) can influence bone and thus it is not surprising that they are also strain dependent. For example, C57BL/6 mice have a higher endosteal bone resorption rate compared to $\mathrm{C} 3 \mathrm{Hmice}$ [26]. Such differences in starting bone volume and bone-remodeling rates could influence skeletal responses to anabolic or catabolic perturbations. In support of this, $\mathrm{C} 3 \mathrm{H}$ mice display less bone loss under disuse conditions and have a reduced anabolic response to mechanical vibration when compared to C57BL/6

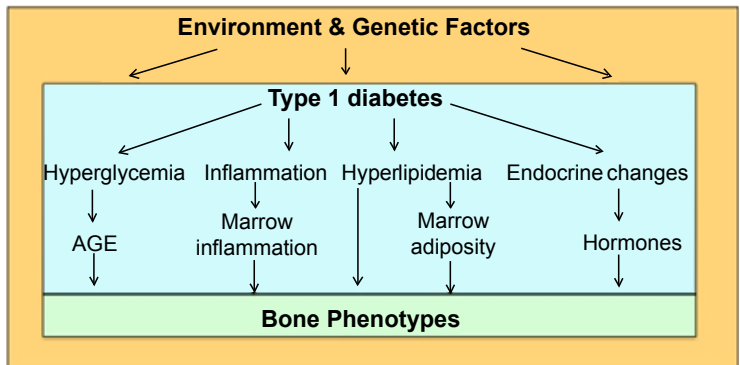

Figure 1: Schematic picture indicating factors thought to contribute to the bone pathophysiology observed in type 1 diabetes.

*Corresponding author: Laura R. McCabe, Departments of Physiology and Radiology, Michigan State University, 2201 Biomedical Physical Science Building East Lansing, MI, USA, 48824, Tel: (517) 884-5152; Fax: (517) 355-5125; E-mail: mccabel@msu.edu

Received July 27, 2012; Accepted September 16, 2012; Published Septembe 22, 2012

Citation: Zhang J, Coe L, Motyl KJ, McCabe LR (2012) Mouse Strain Dependen and Independent Effects of Type 1 Diabetic Bone Pathology. J Diabetes Metab S1:008. doi:10.4172/2155-6156.S1-008

Copyright: ( $) 2012$ Zhang J, et al. This is an open-access article distributed unde the terms of the Creative Commons Attribution License, which permits unrestricted use, distribution, and reproduction in any medium, provided the original author and source are credited. 
mice $[27,28]$. Thus, the selection of mouse strain is a key when planning studies that address changes in bone phenotype.

Interestingly, while mechanisms of T1D osteoporosis have been studied in several rodent models, the contribution of mouse strain to the level of bone loss has not been fully addressed. Here, we examined if genetic differences can impact the skeletal response to T1D by directly comparing general parameters of T1D-induced bone loss in $\mathrm{Balb} / \mathrm{c}, \mathrm{C} 57 \mathrm{~B} / 6$, and $129 / \mathrm{Sv}$ mice, which are commonly used inbred mice strains. We found that T1D caused bone loss in all strains, but the magnitude of bone loss was greatest in 129/Sv. These data provide a strong rationale for additional studies designed to exploit mouse strain/genetic differences in T1D bone pathologies as a way to identify mechanisms regulating bone loss in this disease so that effective therapies can be developed to treat or prevent bone loss.

\section{Methods}

\section{Diabetic mouse models}

Adult (15-16 weeks) Balb/c, C57BL/6 and 129/Sv strains of male mice were obtained from Harlan Laboratories (Houston, TX). Type I diabetes was induced by 5 daily intraperitoneal injections with streptozotocin (STZ) $(40 \mu \mathrm{g} / \mathrm{g}$ body weight in $0.1 \mathrm{M}$ citrate buffer), a pharmacological agent that is toxic to pancreatic insulin secreting beta islet cells. Control mice were injected with citrate buffer alone. Diabetes was confirmed (12 days after the start of diabetes induction) and monitored by blood glucose measurements, $>300 \mathrm{mg} / \mathrm{dl}$ was considered diabetic. Specifically, one drop of blood was obtained from the saphenous vein and blood glucose measured using an Accu-Check compact glucometer (Roche Diagnostics Corporation, Indianapolis, IN). Forty days after the first STZ injection, the mice were euthanized and total body, tibialis anterior, and subcutaneous femoral fat pad masses were recorded. All mice were kept on a light/dark (12 h/12 h) cyle at $23^{\circ} \mathrm{C}$, and received food (standard lab chow) and water ad libitum. The Michigan State University Institutional Animal Care and Use Committee approved all animal procedures.

\section{RNA analysis}

Whole tibiae were isolated, crushed and RNA extracted using Tri Reagent according to manufacture protocol (Molecular Research Center Inc., Cincinnati, OH). RNA integrity was verified by formaldehydeagarose gel electrophoresis. Synthesis of cDNA was performed using the Superscript II kit with as described by the manufacturer (Invitrogen, Carlsbad, CA). cDNA was amplified by PCR using the iQ SYBR Green Supermix (Bio-Rad, Hercules, CA). Forward and reverse primers for aP2, HPRT (not modulated under diabetic conditions), osteocalcin (OC), and Trap5 were amplified using primers previously described [7,29]. Real time PCR was carried out for 40 cycles using the iCycler (Bio-Rad,Hercules, CA). Each cycle consised of $95^{\circ} \mathrm{C}$ for 15 seonds, $60^{\circ} \mathrm{C}$ for 30 seconds (except for OC, which had an annealing temperatre of $65^{\circ}$ ) and $72^{\circ} \mathrm{C}$ for 30 seconds. RNA-free samples, a negative control, did not produce amplicons. Melting curve and gel analyses (sizing and sequencing) verified single products of the appropriate base pair size.

\section{Micro-computed Computed Tomography ( $\mu$ CT)analysis}

Femurs were scanned using the GE Explore $\mu \mathrm{CT}$ system at a voxel resolution of $20 \mathrm{um}$ from 720 views a beam strength of $80 \mathrm{kvp}$ and $450 \mathrm{uA}$. Scans included bones from each condition and a phantom bone to standardize the grayscale values and maintain consistency between runs. Using the systems auto-threshold (1400) and an isosurface analysis, bone volume fraction (BVF), BMD and BMC, were measured in the trabecular region, $0.17 \mathrm{~mm}$ distal of the growth plate. The GE Microview Software was used for visualization and analysis of volumetric image data computed trabecular densities.

\section{Statistical analysis}

All statistical analyses were performed using SPSS data analysis program for ANOVA comparisons using Tukey test. A p-value of less than 0.05 was considered statistically significant. Values are expressed as averages \pm SE.

\section{Results}

\section{STZ-induced T1D causes loss of body, muscle and fat mass irrespectivef strain}

Various animal models have been developed and used to identify the mechanisms of diabetes-associated complications. Some mouse models become spontaneously diabetic such as the non-obese diabetic mice [10]. Other T1-diabetic models are pharmacologically induced [11], including low-dose STZ injection which causes repetitive damage to the pancreatic $\beta$-cells and hence the loss of insulin secretion. This approach is successful in different mouse genetic backgrounds [30]. To address the role of mouse genotype/strain on T1D bone pathology, we used the multiple low dose STZ injection method to induce T1D in $\mathrm{Balb} / \mathrm{c}, \mathrm{C} 57 \mathrm{BL} / 6$ and $129 / \mathrm{Sv}$ mice, strains that are commonly used in research. STZ induced hyperglycemia in all mice. Interestingly, T1D $\mathrm{Balb} / \mathrm{c}$ mice had the highest non-fasting blood glucose levels $(647 \pm 33$ $\mathrm{mg} / \mathrm{dl})$ when compared to C57BL/6 mice $(503 \pm 24 \mathrm{mg} / \mathrm{dl})$ and $129 /$ Sv mice $(429 \pm 28 \mathrm{mg} / \mathrm{dl})$. Strain differences in blood glucose levels were also seen in control mice where control C57BL/6 mice had the highest level of glucose $(197 \pm 9 \mathrm{mg} / \mathrm{dl}$; Figure $2 \mathrm{~A})$ compared to the other strains, consistent with a previous report [30]. The relatively high T1D glucose level and low basal glucose level in Balb/c mice suggests that the serum glucose level in Balb/c mice is more sensitive to STZinduced T1D compared to the other two mice strains. Both the control and T1D129/Sv mice had the lowest blood glucose levels compared the other two strains (Balb/c and C57BL/6).

Next, we examined general body parameters. Body weights differed in control mice, being significantly greater in C57BL/6 $(29.8 \pm 0.5 \mathrm{~g})$ compared to $129 / \mathrm{Sv}(27.5 \pm 0.5 \mathrm{~g})$ or Balb/c $(27.8 \pm 0.5 \mathrm{~g})$ mice. STZinduced T1D caused weight loss in all mouse strains, but the percentage change (from genotype controls) was the least in the C57BL/6 mice, likely because weight before and after STZ injection was highest for C57BL/6 mice compared to other strains (Figure 2B). Examination of muscle mass demonstrated that $129 / \mathrm{Sv}$ mice had the greatest muscle mass of all strains, despite having the lowest body weight of all strains (Figure 2C). This difference was evident both before and after STZ injection. Overall, T1D induced a loss of muscle mass (tibialis anterior) in all strains to a similar extent. Examination of femoral fat pad mass in control mice indicated that $\mathrm{Balb} / \mathrm{c}$ mice had the smallest fat depot $(13.1 \pm 0.6 \mathrm{~g})$ compared to C57BL/6 $(34.1 \pm 2.7 \mathrm{~g})$ and $129 / \mathrm{Sv}(33.7 \pm$ $1.6 \mathrm{~g}$ ). STZ induced T1D caused fat pad mass loss in all mice regardless of strain, however there were significant differences in the amount of fat lost (Figure 2D). The most dramatic T1D-induced decrease in femoral fat mass was seen in 129/Sv mice (from $33.7 \pm 1.6 \mathrm{~g}$ to $4.9 \pm 0.4$ g). The observed general body changes were also seen in spontaneous T1D mouse models. Specifically, spontaneous T1D models (such as the

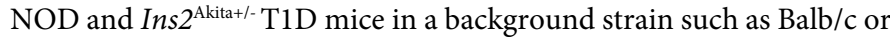
C57BL/6) demonstrate increased serum glucose levels, decreased body, fat pad and tibialis weight [10,31]. Thus the general phenotype of STZinduced T1D mice is not a direct artificial effect of STZ [10]. 
A



C

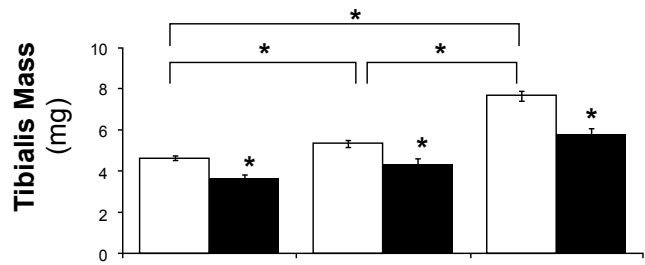

D

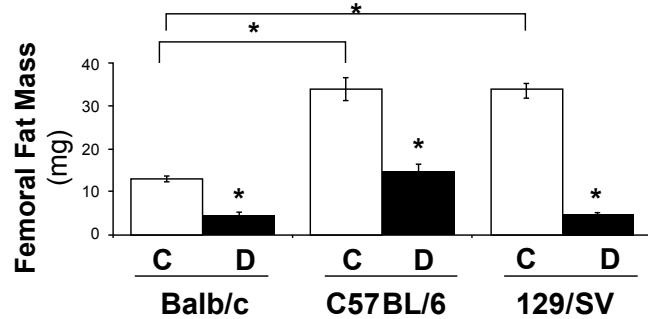

Figure 2: Body parameters of STZ induced T1D in the 15-week old Balb/c, C57BL/6, and 129/Sv mice. 15-week old Balb/c, C57BL/6, and 129/ $\mathrm{Sv}$ were treated with vehicle or $40 \mathrm{mg} / \mathrm{kg}$ STZ for 5 consecutive days and then harvested at 40 days post first injection (dpi). General body parameters were measured at $40 \mathrm{dpi}$. STZ-induced diabetes caused an (A) increase in blood glucose levels and $(B)$ decrease in body mass independent of mouse strain. However, the magnitude of blood glucose induction by STZ was strain dependent. Both (C) Lean muscle (tibialis anterior) and (D) femoral fat mass were decreased by T1D. White bars represent the control mice and the black bars represent diabetic mice for each strain. Bars represent the average value $\pm \mathrm{SE}\left(\mathrm{n} \geq 8-10\right.$ per group); ${ }^{*}$ denotes $\mathrm{p}<0.05$

\section{STZ-induced T1D causes bone loss irrespective of strain, but differed imagnitude}

Although different individual strains have been used to study T1Dinduced bone loss, few studies compared the diabetic bone phenotypes in different mouse strains. Decreased bone formation and bone loss are evident in diabetic animals from a variety of strains, including nonobese diabetic mice [10,32], CD-1 [33], C57BL/6 [34], and db/db in C57BL/6 background [35]. Also, given that this response is similar to what is seen in humans with type I diabetes [36], we reasoned that strain differences might only alter the magnitude of effects on bone in response to the STZ-induced T1D. Therefore, we imaged mouse femur bones by $\mu \mathrm{CT}$ and identified that T1D results in trabecular bone loss in all mouse strains studied (Figure 3A). 129/Sv and Balb/c mice havesignificantly higher basal BVF when compared to C57BL/6. This is consistent with previous findings showing a higher basal BVF in Balb/c compared to C57BL/6 mice [25]. However, after STZ-T1D induction, 129/SV mice demonstrate similar low BVF as C57BL/6 mice, significantly lower than that of Balb/c mice. Therefore, $129 / \mathrm{Sv}$ has a significantly greater

decrease in BVF (58.7\%) compared to Balb/c (37.1\%) and C57BL/6 (31.3\%) mice (Figure 3B). This suggests that STZ induced T1D in129/ $\mathrm{Sv}$ mice leads to a more severe bone loss phenotype. Similar to the STZ models, bone loss has been observed for spontaneous T1D mouse models in various mice backgrounds $[4,7,10,11]$ confirming that this response is a T1D complication.

STZ-induced T1D affected molecular markers of bone phenotype similarly among different se strains

To assess if T1D decreased osteoblast activity and/or increased osteoclast activity and/or affected bone marrow adiposity, we examined molecular markers of bone phenotype and pathology in all mouse bones. We did not observe a significant strain difference in the level of an osteoclast marker, Trap5 mRNA levels, even after STZ-induced diabetes (Figure 4A). However, an osteoblast marker (OC mRNA levels) was consistently decreased after STZ-induced T1D in all mouse strains. No significant difference in the extent of the reduction was observed (Figure $4 \mathrm{~B}$ ). In addition,addition, all T1D mice showed an up regulation of marrow adiposity marker aP2 after STZ-induced T1D with no significant difference in magnitude between strains (Figure 4C). This suggests that STZ-induced T1D results in consistent decreased osteoblast activity, unchanged osteoclast activity and increased marrow adiposity concurrent with bone loss.

\section{Discussion}

As many as $50 \%$ adults with T1D exhibit bone loss and an increased

A
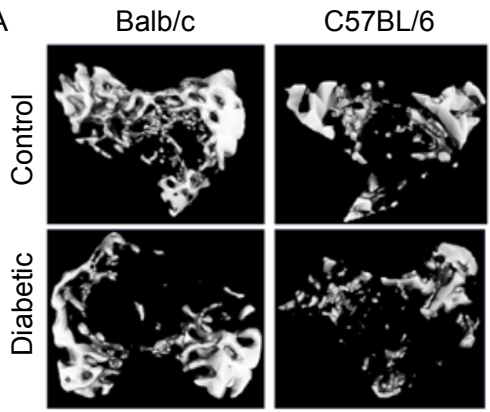

B

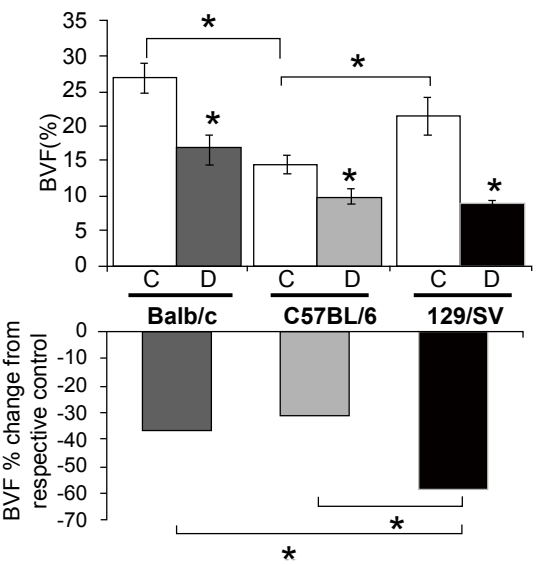

Figure 3: Mouse strain affects the magnitude of STZ-induced T1D reduction in bone volume fraction. Trabecular bone volume fraction (BVF) was determined in the region of the distal femur. 129/Sv lost significantly more BVF compared to Balb/c and C57BL/6 diabetic mice. Percent BVF was calculated using $\mu \mathrm{CT}$ imaging technique and displayed relative to individual strain's control. Bars represent the average value \pm SE ( $n \geq 8-10$ per group); * denotes $p<0.05$. 
A

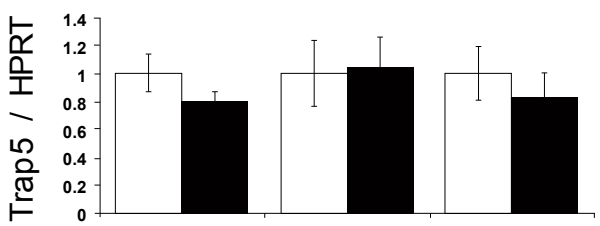

B

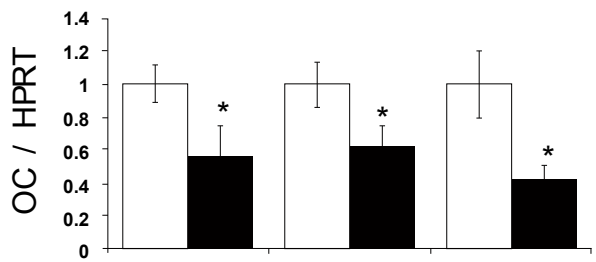

C

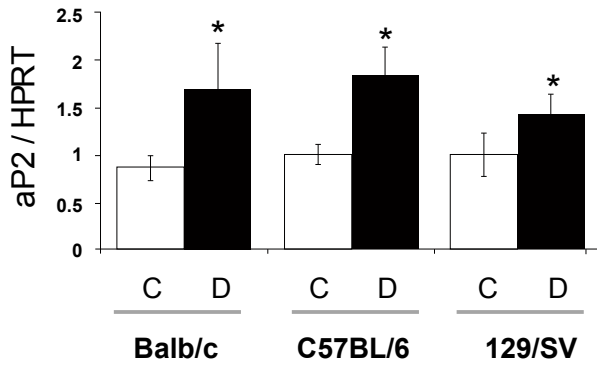

Figure 4: Unchanged bone resorption, decreased bone formation and increased marrow adiposity were observed in T1D mice of all strains. RNA was obtained from mouse tibias and analyzed for levels of genes known to be bone phenotype markers. Levels were expressed relative to HPRT, a house keeping gene that did not modulate among strains nor were its levels modified by T1D. (A) RNA analysis of the resorption marker Trap5 demonstrated no significant change in all three mice strains. (B) Bone formation marker, OC, decreased similarly in all three strains studied. (C) Elevated aP2 expression was observed in all three mice strains. Control (white bars) and diabetic (black bars) mice for each strain were examined. Bars represent the average value \pm $\mathrm{SE}\left(\mathrm{n} \geq 8-10\right.$ per group); ${ }^{*}$ denotes $\mathrm{p}<0.05$.

risk of fractures, which if they occur affect the overall quality of life in T1D patients. Identification of the factors contributing to T1D bone loss is critical to understanding the underlying pathogenesis of T1D osteoporosis so that effective therapies can be developed to treat or prevent bone loss [37]. Understanding the influence of mouse strain/ genotype on the extent of T1D induced bone loss serves several key points: 1) addresses if genetic factors can impact the extent of bone pathology, 2) identifies differences among mouse strains that can be utilized in the future to assess bone pathology modifiers, and 3) provides a data base that can be referred to when selecting a mouse strain for a T1D study. Here, our findings reinforce that overall skeletal responses to T1D are consistent across mouse strains and therefore not completely genetically dependent. The magnitude of disease and bone loss effects, on the other hand, was sensitive to mouse strain/genotype differences.

We observed differences in blood glucose levels between T1D mice of different strains: this parameter, considered to characterize disease severity and/or responsiveness to STZ, has a genetic component as has been previously reported; specifically, studies show that the ability of STZ to induced T1D is mouse strain specific and that certain mouse strains need higher doses of STZ to induce T1D [30]. In our study all mice developed T1D with the same STZ dosing/treatment regime. However, the $129 / \mathrm{Sv}$ mice exhibited the lowest non-fasting blood glucose levels, which were still well above our cut off for diabetes (429 versus $300 \mathrm{mg} / \mathrm{dl}$ ). With regard to bone, the increase in blood glucose levels/disease severity did not directly correlate with the amount of bone loss ultimately observed. Specifically, even though the T1D 129/ Sv mice had the lowest blood glucose levels they lost the most bone. This was surprising given that previous studies indicate a relationship between mouse blood glucose levels and osteoblast death in bone [38], which can contribute to T1D bone loss. The discordance between blood glucose levels and bone loss may result from the presence of a maximum level of hyperglycemia and/or disease severity wherebone loss is no longer proportional to disease severity (i.e, increases in hyperglycemia beyond $500 \mathrm{mg} / \mathrm{dl}$ does not cause proportional losses in bone).

We found that T1D mice from all strains, Balb/c, C57BL/6 and 129 Sv mice, consistently demonstrated decreased bone density, the extent of which was modified by mouse strain. Differences in the magnitude of T1D bone loss between mice might be explained by different genetic anabolic responses/properties. This is supported by the previous observation that there is a genetic association between bone density and serum levels of IGF-1 in the F2 progeny of the cross of LID (with a mixed genetic background of FVB/N, C57BL, and 129Sv) and ALSKO mice (with a mixed genetic background of $\mathrm{BALB} / \mathrm{c}$ and 129/Sv) [39]. It is also found that $\mathrm{C} 3 \mathrm{H}$ mice have higher serum levels of growth hormone [40,41] and IGF-1 [42], compared to C57BL/6. The specific factors that account for the strain-dependent contributions to the extent of T1D bone loss remain to be identified.

The 129/Sv strain demonstrated the greatest level of bone loss. This strain is commonly used to create the knockout mice and embryonic stem cell cultures [43] and thus if a genetically modified mouse colony is not fully backcrossed into a new strain, it can contain some $129 / \mathrm{Sv}$ genome which can influence its responsiveness to T1D, for example. Given the role of mouse strains in regulating overall basal levels of bone density as well as the degree of disease severity and bone responses to disease, working with mice that have known similar backgrounds and/or are litter mates is critical to avoid errors in data interpretation. In addition to bone density differences, the immune system differs between mouse strains including Balb/c and C57BL/6 mice. Balb/c mice have more plasma cytoid dendritic cells in their lymphoid organs compared to C57BL/6 and the numbers of other subsets of dendritic cells varied between the strains [44,45]. Differences in acute inflammatory responses in 129/Sv, Balb/c and C57BL6 mice have also been reported [46]. In addition, when fed the same diet, 129/ $\mathrm{Sv}$ mice absorb significantly more cholesterol than C57BL/6 mice. Correspondingly, 129/Sv mice have markedly lower rates of hepatic and intestinal cholesterol synthesis compared to C57BL/6 mice [47]. The varied immune sensitivity and metabolism in different mice strains might contribute to their unique T1D bone phenotype. More endpoint analyses, e.g. bone histomorphometry and bone marrow cell/ peripheral blood cell profiles should be studied in the future to support and explain the observed bone phenotype in this study.

Using different mouse models, we and others demonstrated that T1D induced bone loss is marked by a predominant suppression in bone formation and increased marrow adiposity $[1,7,11,48]$. Therefore the bone formation marker (OC), bone resorption marker (Trap5) and marrow adiposity marker ( $\mathrm{aP} 2)$ were examined here. Because of differences in the amount of bone loss, we expected to see differences in the molecular bone parameters, but did not. This suggests that difference in bone phenotype cannot be fully explained by differences in markers of osteoclast/osteoblast activity and marrrow adiposity. This may be the result of looking at only one time point. In addition 
to bone deposition markers, bone turnover rate (affected by the in vivo metabolic and anabolic status) might be another factor that should be taken into account. More bone markers, particularly bone turnover markers such as serum alkaline phosphatase, procollagen 1 extension peptide, urine or serum $\mathrm{N}$-telopeptide, c-telopeptide and deoxypyridinoline should be examine to investigate the underlying mechanisms. Other mechanisms to explain the strain dependent severity of bone loss in T1D also await further elucidation. In summary, these data provide a foundation for understanding how mouse strain influences skeletal responses to T1D. The data also provide a strong rationale for additional future studies designed to exploit mouse strain/ genetic differences in T1D bone pathologies to identify mechanisms regulating bone loss in this disease.

\section{Acknowledgment} LRM

Funded by grants from the American Diabetes Association (7-07-RA-105) to

\section{References}

1. McCabe LR (2007) Understanding the pathology and mechanisms of type I diabetic bone loss. J Cell Biochem 102: 1343-1357.

2. Wu KK, Huan $Y(2008)$ Streptozotocin-induced diabetic models in mice and rats. Curr Protoc Pharmacol: Unit5 47

3. Mathiassen B, Nielsen S, Johansen JS, Hartwell D, Ditzel J, et al. (1990) Long-term bone loss in insulin-dependent diabetic patients with microvascular complications. J Diabet Complications 4: 145-149.

4. Motyl K, McCabe LR (2009) Streptozotocin, type I diabetes severity and bone. Biol Proced Online 11: 296-315.

5. Botolin S, McCabe LR (2006) Chronic hyperglycemia modulates osteoblas gene expression through osmotic and non-osmotic pathways. J Cell Biochem 99: 411-424.

6. Motyl KJ, McCabe LR, Schwartz AV (2010) Bone and glucose metabolism: a two-way street. Arch Biochem Biophys 503: 2-10.

7. Motyl KJ, Botolin S, Irwin R, Appledorn DM, Kadakia T, et al. (2009) Bone inflammation and altered gene expression with type I diabetes early onset. J Cell Physiol 218: 575-583.

8. McCabe L, Zhang J, Raehtz S (2011) Understanding the skeletal pathology of type 1 and 2 diabetes mellitus. Crit Rev Eukaryot Gene Expr 21: 187-206.

9. Graves DT, Liu R, Oates TW (2007) Diabetes-enhanced inflammation and apoptosis: impact on periodontal pathosis. Periodontol 2000 45: 128-137.

10. Botolin S, McCabe LR (2007) Bone loss and increased bone adiposity in spontaneous and pharmacologically induced diabetic mice. Endocrinology 148 : 198-205.

11. Botolin S, Faugere MC, Malluche H, Orth M, Meyer R, et al. (2005) Increased bone adiposity and peroxisomal proliferator-activated receptor-gamma2 expression in type I diabetic mice. Endocrinology 146: 3622-3631.

12. Di lorgi N, Rosol M, Mittelman SD, Gilsanz V (2008) Reciprocal relation between marrow adiposity and the amount of bone in the axial and appendicular skeleton of young adults. J Clin Endocrinol Metab 93: 2281-2286.

13. Dixit PK, Stern AM (1979) Effect of insulin on the incorporation of citrate and calcium into the bones of alloxan-diabetic rats. Calcif Tissue Int 27: 227-232.

14. Motyl KJ, McCabe LR (2009) Leptin treatment prevents type I diabetic marrow adiposity but not bone loss in mice. J Cell Physiol 218: 376-384.

15. Botolin S, McCabe LR (2006) Inhibition of PPARgamma prevents type I diabetic bone marrow adiposity but not bone loss. J Cell Physiol 209: 967-976.

16. Breyer MD, Bottinger E, Brosius FC 3rd, Coffman TM, Harris RC, et al. (2005) Mouse models of diabetic nephropathy. J Am Soc Nephrol 16: 27-45.

17. Christian JC, Yu PL, Slemenda CW, Johnston CC Jr (1989) Heritability of bone mass: a longitudinal study in aging male twins. Am J Hum Genet 44: 429-433.

18. Kelly PJ, Nguyen T, Hopper J, Pocock N, Sambrook P, et al. (1993) Changes in axial bone density with age: a twin study. J Bone Miner Res 8: 11-17.
19. McKay HA, Bailey DA, Wilkinson AA, Houston CS (1994) Familial comparison of bone mineral density at the proximal femur and lumbar spine. Bone Miner 24: 95-107.

20. Koller DL, Schriefer J, Sun Q, Shultz KL, Donahue LR, et al. (2003) Genetic effects for femoral biomechanics, structure, and density in C57BL/6J and $\mathrm{C} 3 \mathrm{H} /$ HeJ inbred mouse strains. J Bone Miner Res 18: 1758-1765.

21. Ishimori N, Li R, Walsh KA, Korstanje R, Rollins JA, et al. (2006) Quantitative trait loci that determine BMD in C57BL/6J and 129S1/SvImJ inbred mice. Bone Miner Res 21: 105-112.

22. Jepsen KJ, Price C, Silkman LJ, Nicholls FH, Nasser P, et al. (2008) Genetic variation in the patterns of skeletal progenitor cell differentiation and progression during endochondral bone formation affects the rate of fracture healing. J Bone Miner Res 23: 1204-1216.

23. Wergedal JE, Sheng MH, Ackert-Bicknell CL, Beamer WG, Baylink DJ (2005) Genetic variation in femur extrinsic strength in 29 different inbred strains of mice is dependent on variations in femur cross-sectional geometry and bone density. Bone 36: 111-122.

24. Turner CH, Hsieh YF, Muller R, Bouxsein ML, Baylink DJ, et al. (2000) Genetic regulation of cortical and trabecular bone strength and microstructure in inbred strains of mice. J Bone Miner Res 15: 1126-1131.

25. Beamer WG, Donahue LR, Rosen CJ, Baylink DJ (1996) Genetic variability in adult bone density among inbred strains of mice. Bone 18: 397-403.

26. Dimai HP, Linkhart TA, Linkhart SG, Donahue LR, Beamer WG, et al. (1998) Alkaline phosphatase levels and osteoprogenitor cell numbers suggest bone formation may contribute to peak bone density differences between two inbred strains of mice. Bone 22: 211-216.

27. Squire M, Donahue LR, Rubin C, Judex S (2004) Genetic variations that regulate bone morphology in the male mouse skeleton do not define its susceptibility to mechanical unloading. Bone $35: 1353-1360$.

28. Judex S, Donahue LR, Rubin C (2002) Genetic predisposition to low bone mass is paralleled by an enhanced sensitivity to signals anabolic to the skeleton. FASEB J 16: 1280-1282.

29. Weghofer M, Karlic H, Haslberger A (2001) Quantitative analysis of immunemediated stimulation of tumor necrosis factor-alpha in macrophages measured at the level of mRNA and protein synthesis. Ann Hematol 80: 733-736.

30. Hayashi K, Kojima R, Ito M (2006) Strain differences in the diabetogenic activity of streptozotocin in mice. Biol Pharm Bull 29: 1110-1119.

31. Barber AJ, Antonetti DA, Kern TS, Reiter CE, Soans RS, et al. (2005) The Ins2Akita mouse as a model of early retinal complications in diabetes. Invest Ophthalmol Vis Sci 46: 2210-2218.

32. Thrailkill KM, Liu L, Wahl EC, Bunn RC, Perrien DS, et al. (2005) Bone formation is impaired in a model of type 1 diabetes. Diabetes 54: 2875-2881.

33. Lu H, Kraut D, Gerstenfeld LC, Graves DT (2003) Diabetes interferes with the bone formation by affecting the expression of transcription factors that regulate osteoblast differentiation. Endocrinology 144: 346-352.

34. Lalla E, Lamster IB, Feit M, Huang L, Spessot A, et al. (2000) Blockade of RAGE suppresses periodontitis-associated bone loss in diabetic mice. J Clin Invest 105: 1117-1124.

35. He H, Liu R, Desta T, Leone C, Gerstenfeld LC, et al. (2004) Diabetes causes decreased osteoclastogenesis, reduced bone formation, and enhanced apoptosis of osteoblastic cells in bacteria stimulated bone loss. Endocrinology 145: $447-452$.

36. Kemink SA, Hermus AR, Swinkels LM, Lutterman JA, Smals AG (2000) Osteopenia in insulin-dependent diabetes mellitus; prevalence and aspects of pathophysiology. J Endocrinol Invest 23: 295-303.

37. Schett G, David JP (2010) The multiple faces of autoimmune-mediated bone loss. Nat Rev Endocrinol 6: 698-706.

38. Coe LM, Irwin R, Lippner D, McCabe LR (2011) The bone marrow microenvironment contributes to type I diabetes induced osteoblast death. $J$ Cell Physiol 226: 477-483.

39. Yakar S, Rosen CJ, Beamer WG, Ackert-Bicknell CL, Wu Y, et al. (2002) Circulating levels of IGF-1 directly regulate bone growth and density. J Clin Invest 110: 771-781.

40. Sinha YN, Salocks CB, Vanderlaan WP (1975) Prolactin and growth hormone 
Citation: Zhang J, Coe L, Motyl KJ, McCabe LR (2012) Mouse Strain Dependent and Independent Effects of Type 1 Diabetic Bone Pathology. J

levels in different inbred strains of mice: patterns in association with estrous cycle, time of day, and perphenazine stimulation. Endocrinology 97: 11121122.

41. Sinha YN, Vlahakis G, Vanderlaan WP (1979) Serum, pituitary and urine concentrations of prolactin and growth hormone in eight strains of mice with varying incidence of mammary tumors. Int J Cancer 24: 430-437.

42. Rosen CJ, Dimai HP, Vereault D, Donahue LR, Beamer WG, et al. (1997) Circulating and skeletal insulin-like growth factor-I (IGF-I) concentrations in two inbred strains of mice with different bone mineral densities. Bone 21: 217-223.

43. Jiang LI, Nadeau JH (2001) 129/Sv mice--a model system for studying germ cell biology and testicular cancer. Mamm Genome 12: 89-94.

44. Flacher V, Douillard P, Ait-Yahia S, Stoitzner P, Clair-Moninot V, et al. (2008) Expression of langerin/CD207 reveals dendritic cell heterogeneity between inbred mouse strains. Immunology 123: 339-347.
45. Asselin-Paturel C, Brizard G, Pin JJ, Briere F, Trinchieri G (2003) Mouse strain differences in plasmacytoid dendritic cell frequency and function revealed by a novel monoclonal antibody. J Immunol 171: 6466-6477.

46. Morris A, Kinnear G, Wan WY, Wyss D, Bahra P, et al. (2008) Comparison of cigarette smoke-induced acute inflammation in multiple strains of mice and the effect of a matrix metalloproteinase inhibitor on these responses. J Pharmacol Exp Ther 327: 851-862.

47. Jolley CD, Dietschy JM, Turley SD (1999) Genetic differences in cholestero absorption in 129/Sv and C57BL/6 mice: effect on cholesterol responsiveness. Am J Physiol 276: G1117-G1124

48. Fowlkes JL, Bunn RC, Liu L, Wahl EC, Coleman HN, et al. (2008) Runt-related transcription factor 2 (RUNX2) and RUNX2-related osteogenic genes are downregulated throughout osteogenesis in type 1 diabetes mellitus. Endocrinology 149: $1697-1704$
This article was originally published in a special issue, Diabetic Osteoporosis handled by Editor(s). Dr. Laura McCabe, Michigan State University, USA 